\title{
Factors Associated with Perceived Time Pressure among Employed Mothers and Fathers
}

\author{
Terrie Fitzpatrick ${ }^{1}$, Bonnie Janzen ${ }^{1}$, Sylvia Abonyi ${ }^{1,2}$, Ivan Kelly ${ }^{3}$ \\ ${ }^{1}$ Department of Community Health \& Epidemiology, University of Saskatchewan, Saskatoon, Canada \\ ${ }^{2}$ Saskatchewan Population Health and Evaluation Research Unit, University of Saskatchewan, Saskatoon, Canada \\ ${ }^{3}$ Department of Educational Psychology \& Special Education, University of Saskatchewan, Saskatoon, Canada \\ Email: bonni.e.janzen@usask.ca
}

Received December $18^{\text {th }}, 2011$; revised January $12^{\text {th }}, 2012$; accepted January $31^{\text {st }}, 2012$

\begin{abstract}
Research suggests that the perception of being pressed for time is increasing in many Western societies and that such perceptions are linked with social and mental well-being. The aim of this study was to clarify the family and work-related characteristics associated with perceived time pressure in a sample of Canadian working mothers and fathers. A telephone survey of 1160 employed parents (674 women and 486 men) conducted in a mid-size Canadian city in 2005 provided the data for this study. Results of the multiple linear regression analyses showed that both role occupancy and role quality was related to perceived time pressure and that the nature of these relationships depended on gender. For mothers, the following factors were associated with increased time pressure: occupancy of an unpaid caregiving role, parenting a child with at least one health/behavioral problem, and the perception of parenting as draining or anxiety provoking. Regarding the paid work environment, women who were categorized as high strain (i.e., high demands/low control) or active (high demands/high control) also reported higher levels of time pressure. For fathers, greater perceived time pressure was associated with: occupancy of the partner role, the perception of parenting as draining, being a multiple job holder and having a high strain (i.e., high demands/low control) or active (high demands/high control) psychosocial work environment. Limitations of the study are discussed as are the policy implications of the findings.
\end{abstract}

Keywords: Time Pressure; Gender; Employment; Parenting

\section{Introduction}

There has been an increasing interest in Canada over the last several decades, both in the academic literature and in the popular press, of issues related to Canadians' quality of life, particularly the balance Canadian workers are able (or unable) to achieve between paid work and family/community life (Brooker \& Hyman, 2010; Hebert \& Grey, 2006). An important component of work-life balance is the amount of time people perceive as having available to meet their role-related obligations - as parents, paid workers, partners and caregivers, among others. Referred to in the literature with a variety of labels"time pressure", "time crunch", "time squeeze"- the perception of not having enough time to do all of the things one needs to get done appears to be on the rise across industrialized nations. In Canada, for example, $16.4 \%$ of the population reported high levels of time pressure in 1992, compared with $19.7 \%$ in 2005 (Brooker \& Hyman, 2010).

What might account for the increase in perceived time pressure? Objective explanations of time pressure point to labour market trends, with both men and women reporting an increasing amount of time spent in both paid and unpaid work over the last 30 years (Jacobs \& Gerson, 2005) as well as an increase in time spent in nonstandard work (i.e., evening, night, split shift or weekends) (Mattingly \& Sayer, 2006). Cultural explanations, on the other hand, have focused on the amplification of consumerism in Western society which drives time intensive activities with "high octane" lifestyles.

Whatever the explanation for the increase in subjective time pressure, evidence suggests that the perception of time pressure varies according to gender, with the research consistently reporting women as being more time stressed than men (Jacobs \& Gerson, 2005; Mattingly \& Sayer, 2006; Marshall, 2006). Although the reason for this gender difference is likely complex, many have pointed to the increased presence of women in the labour force in combination with their continued greater responsibility than men in regard to child rearing, performing household chores, and caring for ageing relatives (Marshall, 2006). In addition to gender, the experience of time pressure is patterned, to a certain extent, according to occupancy in major social roles. For example, parents, particularly mothers, face greater time strain than women who do not have children (Beaujot \& Andersen, 2007; Bellavia \& Frone, 2005; Zukewich, 2003), as do full-time employed adults, compared to those not in the labour force or working part-time (Beaujot \& Andersen, 2007). Among parents, the relationship between time pressure and marital/partner status has produced less consistent findings. In Canada in 2006, single parent families accounted for $16 \%$ of all families, up from $11 \%$ in 1981 (Statistics Canada, 2008). Single parents face the same challenge of supporting the family and spending time with their children as partnered parents but often with fewer economic resources and a lack of support in childcare (Milkie, Mattingly, Nomaguchi, Bianchi, \& Robinson, 2004). Further, adding to the potential for time pressure, the vast majority of single parents are also in the paid labour force (Galarneu, 2005). To date, however, research examining the relationship between partner status and time pressure among 
mothers has produced conflicted findings (Baxter \& Alexander, 2008; Milkie et al., 2004; Roxburgh, 2002). While there is minimal research on time pressure among single mothers the information about single fathers is even less available. An important objective of this research was to examine the perception of time pressure among employed, single parent mothers and fathers, a growing family type in Canada (Statistics Canada, 2008).

In addition to the growing number of families headed by a lone parent in Canada, particularly single fathers, there has been an increase in the proportion of working-age adults who are providing care to someone other than their children. In 2007, among Canadians 45 years of age and older, 19\% of men and $22 \%$ of women, or 2.7 million Canadians, reported providing assistance to a senior with a chronic health condition (Cranswick \& Dosman, 2008). Caregivers may experience higher levels of time pressure than other Canadians given their multiple responsibilities; that is, in 2007, almost three-quarters of 45 - 64 years old caregivers were partnered and $57 \%$ were employed. In addition, approximately $40 \%$ of caregivers were younger than 54 years of age - a stage in life which typically means many still have children residing in the home. An additional objective of this study, therefore, was to examine whether caregiving responsibilities, in addition to employment and child rearing responsibilities, increase Canadians' vulnerability to perceptions of time pressure. This is an important objective, given two considerations: 1) by 2036, seniors are expected to comprise $22 \%$ of the Canadian population; and 2) community and health care resources will likely not be able to meet the demands of this aging population and it is predicted that informal support provided by family and friends will become even more crucial (Cranswick \& Dosman, 2008; Duxbury et al., 2009).

In addition to role occupancy, research suggests perceived time pressure may be patterned according to the quality of the roles occupied (Roxburgh, 2002). That is, two individuals could occupy the same number and types of roles, but be exposed to very different demands within those roles. For example, lower paying jobs tend to be characterized by fewer chances to learn and develop skills, higher psychological work load, and less job variety-characteristics which in turn have been associated with a greater risk of poor mental health (Stansfeld \& Candy, 2006; Karasek et al., 1998). Resources in the work environment have also been recognized as playing an important role in offsetting the potential harmful effects of a highly demanding job. A sense of control over work activities has been identified as particularly critical for promoting health and well-being (Griffin, Fuhrer, Stansfeld, \& Marmot, 2002). However, the majority of research to date has focused on role occupancy in relation to time pressure, with inferences made concerning role quality on the basis of relatively crude measures of objective role characteristics (e.g. hours of employment, number of children). Thus, an important objective of this study was to examine both objective and subjective characteristics of work and family roles in relation to perceived time pressure.

A final objective of this research was to examine how gender may modify associations between work and family role occupancy, role quality, and subjective time pressure. Considerable evidence suggests that gender shapes many of the opportunities and constraints associated with work and family role configurations, which may in turn, impact on perceptions of time pressure (Roxburgh, 2002; MacDonald, Phipps, \& Lethbridge,
2005). For example, despite women's increasing labour force presence, and men's increasing participation in housework and childrearing activities in the last several decades, employed mothers still retain primary responsibility for the bulk of domestic work in two-parent households (Marshall, 2006). The implication is that men and women occupying the same role configuration (e.g. employed parent) may experience that role in qualitatively different ways with consequences for the subjective experience of time pressure. In addition, some evidence suggests that the factors associated with perceived time pressure may differ by gender, with men more influenced by work characteristics and women by family factors (Nomaguchi et al., 2005).

The overall objective of this study was to examine the patterning of perceived time pressure according to role occupancy and role characteristics in a sample of employed parents. More specifically, three research questions guided the study:

1) How is role occupancy associated with perceived time pressure? That is, does the additional role of partner and/or caregiver increase the perception of time pressure?

2) How are the characteristics of work and family roles associated with perceived time pressure?

3) Does the relationship between role occupancy, role characteristics and perceived time pressure vary according to gender?

Understanding the factors associated with perceived time pressure is important for public health, particularly given research suggesting that perceptions of time pressure are increasing in Western society and that such perceptions are linked with social and mental well-being. That is, compared to individuals who report lower levels of subjective time pressure, those with higher perceived "time crunch" are more likely to report distress and depression (Roxburgh, 2004), stress (Hilbrecht, 2009; Zuzanek, 2004), insomnia (Zuzanek, 2004), poor self-rated health (Hebert \& Grey, 2006) and are less likely to report happiness and satisfaction with life (Nomaguchi, Milkie, \& Bianchi, 2005).

\section{Method}

\section{Procedures}

The Gender, Work, and Family Health Survey, conducted in Saskatoon Canada in 2005 (Dziak et al., 2010; Tao et al., 2010) provided the data for this study. Telephone interviewers randomly selected registered phone numbers within the city limits and one person per household was chosen to complete a 40 minute survey. Eligible participants were those between the ages of 25 and 50 years, English speaking, employed at least part-time, and the parent of at least one child under the age of 20. Telephone interviews were conducted using a computerassisted telephone interviewing system. The sample had near equal participant proportions in terms of age (25 - 34 and 35 50 ), gender, education (high school or less, some post secondary, university/college).

Of the 5300 eligible individuals contacted, 1160 (674 women and $486 \mathrm{men}$ ) were interviewed successfully. To examine the potential for selection bias, we compared the distribution of our respondents' answers with those from the Canadian Community Health Survey, Cycle 3.1 (CCHS) on similar questions (Statistics Canada, 2005). The response rate of the CCHS was $78.9 \%$. Although the CCHS is a nation-wide survey, our com- 
parison was restricted to CCHS respondents who were residing in the same city as our study participants, employed, in a similar age bracket, and were the parent of at least one child living in the household. As expected, compared to respondents from the CCHS 3.1, our sample was significantly younger and had lower educational attainment. Although our respondents reported significantly higher levels of psychological distress, no statistically significant differences between the two samples emerged in terms of gender, weekly work hours, self-rated health, or in the proportion reporting at least one chronic health condition. The study was approved by the University of Saskatchewan's Behavioural Research Ethics Board.

\section{Measures}

The dependent variable was measured using Roxburgh's (2002) time pressure scale. This 9-item measure requires participants to indicate, on a 4 point Likert scale ranging from strongly disagree (1) to strongly agree (4), the extent to which each item reflected their lives in the last year. Sample items include: "You never seem to have enough time to get everything done", "You feel pressed for time", "You feel rushed to do the things that you have to do" and "There just don't seem to be enough hours in the day". Participant scores can range from 9 to 36 with higher scores indicating greater perceived time pressure. A Cronbach alpha of 76 in the present study indicated that the time pressure scale had acceptable internal consistency.

Socio-demographic characteristics included participants' age, sex, educational attainment (university/college graduate; some post-secondary; high school or less), and perceived income adequacy. Perceived income adequacy was assessed with the statement "We have enough money to cover basic needs for food, housing and clothing" with which participants were asked to indicate their agreement on a scale from one (strongly disagree) to four (strongly agree). Due to a skewed distribution, participant responses to the income adequacy question were collapsed into two categories: strongly agree/agree and strongly disagree/disagree.

All participants in this study were employed parents. The roles which did vary and were examined in this study were those of partner and caregiver. Partner status, was a dichotomous variable based on current marital status. Partnered individuals were those who indicated that they were married or living with a partner, and the unpartnered were those who were separated, divorced, widowed, or never married. Participants were categorized as being caregivers (or not) based on their response to the question: "Other than your child, is there a friend or family member living with you or not, to whom you provide special care or attention because of a handicap, illness or old age?"

Several questions assessed key characteristics of paid work. Objective work characteristics included whether the individual worked long hours (50 or more hours/wk), work schedule (regular daytime shift or "other") and whether the participant held more than one job simultaneously (yes/no). Subjective work characteristics were assessed by the Job Content Questionnaire (JCQ; Karasek et al., 1998). JCQ items combine to assess various components of job quality, with nine items measuring decision latitude (authority to make decisions concerning work, ability to use one's skills in doing work) and ten items measuring psychological job demands (effort, pace and amount of work, conflicting demands). The questionnaire items were coded from 1 (strongly agree) to 4 (strongly disagree) accord- ing to the degree to which respondents agreed with each statement and scores for each scale were calculated by summing the item scores. A higher score for each scale indicates greater job demands and decision latitude. Cronbach's alpha for decision latitude and job demands was .74 and .64, respectively. To better represent Karasek's proposed model of job strain, participants' scores on the job demands and decision latitude scales were then categorized using median splits (Vermeulen \& Mustard, 2000) resulting in four dimensions of psychosocial work quality: high strain (high job demands/low decision latitude), low strain (low job demands, high decision latitude), active (high job demands, high decision latitude) and passive (low job demands, low decision latitude). Evidence in support of the validity and reliability of the JCQ scales has been reported in numerous international studies (Karasek et al., 1998).

Family role characteristics included the number of children (one, two, or three or more) and the presence of at least one child age 5 years or younger in the household (yes/no). Participants were also asked to indicate whether any of their children had experienced one or more of the following issues in the previous year: chronic disease or disability, frequent minor illnesses, emotional problems, alcohol or substance abuse problems, problems at school or work, legal problems, or difficulty getting along with people (Voydanoff, 2005). Participants' affirmative responses to this question were summed and subsequently re-categorized into a dichotomous variable with the following outcomes: no problems or one or more problems. Regarding subjective family role characteristics, based on questions from the Northern Ontario Perinatal and Child Health Survey (2002), participants were asked to indicate their extent of agreement (strongly disagree, disagree, agree, strongly agree) with two statements: "parenting leaves you feeling drained and exhausted" and "being a parent makes you tense and anxious". Due to a skewed distribution, participant responses to the "tense and anxious" question was dichotomized (strongly agree/agree; strongly disagree/disagree). Perceived assistance with housework (Berkman, 2001) was measured with the question "Is there someone available to help you with daily chores?" to which participants were asked to indicate on a five point scale from none of the time to all of the time. Satisfaction with family-related services was assessed with the question "How satisfied are you with the help you receive from the supports and services available to you and your child?" Possible responses included: very unsatisfied, somewhat unsatisfied, neutral, somewhat satisfied and very satisfied. Higher scores indicate greater satisfaction. Social support was assessed with Berkman's (2001) 5 -item scale in which respondents were asked to identify the amount of time $(1=$ none of the time to $5=$ all of the time) that they perceived various types of social support were available to them. Item examples include: "Is there someone available to give you advice about a problem?" and "Is there someone available to you who shows you love and affection?". Higher scores indicate greater perceived social support. Cronbach alpha for the social support scale was .77 .

\section{Analysis}

Initial analyses involved the calculation of Pearson product correlation coefficients between the continuous scale study variables. Bivariate analyses were conducted to examine, according to gender, differences in socio-demographic characteristics, work and family roles and characteristics and perceived 
time pressure. Differences between mothers and fathers were tested using chi-square tests for categorical variables and t-tests for continuous measures. Bivariate and multivariable analyses were used to address the research questions. Initial analyses involved chi-square tests to examine the distribution of each of the study variables by gender. A series of one-way ANOVAs were then conducted to examine how perceived time pressure was patterned according to each of the study variables and by gender.

Hierarchical multiple linear regression was used to examine which factors were most strongly related to perceived time pressure. To assess whether the relationship between the study variables and perceived time pressure varied by gender, analyses were conducted separately for men and women. Independent variables were entered into the regression equation in four blocks, the grouping and sequence of entry theoretically guided by our research questions: 1) sociodemographic characteristics (age, educational attainment, perceived income adequacy); 2) role occupancy (partner and caregiving status); 3) family characteristics (number of children, presence of young children in the household, the presence of a child with a health/behavioral problem, perception of parenting as draining/anxiety provoking, assistance with household chores, satisfaction with familyrelated services, social support); and 4) work characteristics (long work hours, work schedule, multiple job holder, job strain).

\section{Results}

Correlations among the continuous variables, displayed in Table 1, are generally low, indicating in relation to each other these measures were adequately orthogonal. Table 2 displays the distribution of the key study variables according to gender. A significantly greater proportion of women than men were college/university graduates. No statistically significant gender differences emerged with respect to age, income adequacy, partner status or taking on additional caregiving responsibilities. Although men were significantly more likely than women to report having help with daily chores, women reported significantly higher levels of perceived social support. No gender differences emerged with respect to number of children, the presence of a young child in the household, having a child with at least one health/behavioral problem, satisfaction with family-related supports and services, or extent of agreement to statements that "parenting makes me feel drained or exhausted" or "parenting makes me feel tense and anxious". With regard to paid work, a higher percentage of men than women reported working 50 hours or more a week and being a multiple job holder whereas women reported greater decision latitude at work than men. Men and women did not differ in terms of work schedule, job demands or job strain. Finally, women perceived themselves as being significantly more time pressured than men $[\mathrm{F}(1,1055)=4.45 ; \mathrm{p}=.03]$ (data not shown).

Results of the linear regression analysis predicting time pressure, reported separately for women and men, are displayed in Tables 3 and 4, respectively. For mothers, the introduction of the sociodemographic characteristics as a block in Step 1, did not make a significant contribution to explaining the dependent variable, nor did any of the characteristics individually. The addition of the role occupancy variables in Step 2 did make a statistically significant contribution to explaining the outcome. More specifically, women who were involved in additional
Table 1.

Pearson correlations for study variables.

\begin{tabular}{|c|c|c|c|c|c|c|c|c|}
\hline Measure & & 1 & 2 & 3 & 4 & 5 & 6 & 7 \\
\hline 1 & Age & & & & & & & \\
\hline 2 & $\begin{array}{l}\text { Psychological } \\
\text { demands }\end{array}$ & .03 & & & & & & \\
\hline 3 & Decision latitude & .08 & .19 & & & & & \\
\hline 4 & $\begin{array}{l}\text { Help with daily } \\
\text { chores }\end{array}$ & .08 & -.06 & .05 & & & & \\
\hline 5 & $\begin{array}{l}\text { Parenting is } \\
\text { draining }\end{array}$ & -.03 & .12 & -.05 & -.04 & & & \\
\hline 6 & $\begin{array}{c}\text { Satisfaction } \\
\text { with supports and } \\
\text { services }\end{array}$ & .17 & -.14 & .15 & .03 & -.09 & & \\
\hline 7 & Social support & .12 & -.11 & .14 & .34 & -.16 & .26 & \\
\hline 8 & Time pressure & -.02 & .22 & -.04 & -.05 & .31 & -.03 & .12 \\
\hline
\end{tabular}

Note. Correlations $\geq .12$ are significant at the .05 level (two-tailed).

caregiving were more time pressured than women who were not, as were women with an inadequate income (compared to adequate). The introduction of family characteristics in Step 3 also significantly contributed to explaining time pressure. Although income adequacy became no longer associated with time pressure, a statistically significant relationship between additional caregiving responsibilities and greater perceived time pressure remained. In addition, women who reported a child with at least one health/behavioral problem had significantly higher levels of time pressure than those mothers who did not, as did mothers who indicated greater agreement with the statements "parenting makes me feel drained or exhausted" or "parenting makes me feel tense and anxious". When work characteristics were entered in the final model, all of the variables associated with time pressure in the previous step remained statistically significant. In addition, women who were categorized as high strain (i.e., high demands/low control) or active (high demands/high control) reported higher levels of time pressure compared to women categorized as low strain (i.e., low demands, low control). In the final model, the independent variables accounted for $16 \%$ of the variance in the dependent variable.

For fathers (Table 4), none of the sociodemographic variables were associated with time pressure in Step 1, nor were any of the role occupancy variables entered in Step 2. In Step 3, with the introduction of family-related characteristics, partner status became statistically significant, with single fathers reporting lower levels of time pressure compared to partnered fathers. In addition, greater agreement with the statement "parenting makes me feel drained or exhausted" was associated with higher perceived time pressure. In the final step, the following variables were associated with greater time pressure for men: occupancy of the partner/marital role, greater endorsement of the statement "parenting makes me feel drained or exhausted" being a multiple job holder and having a high strain (i.e., high demands/low control) or active (high demands/high control) work environment compared to low strain (i.e., low demands, low control). In the final model, the independent variables together accounted for $14 \%$ of the variance in the dependent variable. 
Table 2.

Sociodemographics, role occupancy and role characteristics, by gender.

\begin{tabular}{|c|c|c|c|}
\hline & Women & Men & $\mathbf{p}$ \\
\hline & \multicolumn{2}{|c|}{$\%$} & \\
\hline \multicolumn{4}{|l|}{ Sociodemographic Characteristics } \\
\hline \multicolumn{4}{|l|}{ Educational attainment } \\
\hline High school or less & 32.6 & 32.7 & \\
\hline Some postsecondary & 29.1 & 38.3 & \\
\hline College/university & 38.3 & 29.0 & .01 \\
\hline \multicolumn{4}{|l|}{ Income adequacy } \\
\hline Adequate & 79.0 & 79.7 & \\
\hline Inadequate & 21.0 & 20.3 & .80 \\
\hline Age (Mean \& SD) & $36.15(7.17)$ & $35.85(7.44)$ & .49 \\
\hline \multicolumn{4}{|l|}{ Role Occupancy } \\
\hline \multicolumn{4}{|l|}{ Partner status } \\
\hline Single & 35.0 & 29.8 & \\
\hline Partnered & 65.0 & 70.2 & .13 \\
\hline \multicolumn{4}{|l|}{ Additional caregiving } \\
\hline Yes & 6.2 & 6.4 & \\
\hline No & 93.8 & 93.6 & .92 \\
\hline \multicolumn{4}{|l|}{ Family Characteristics } \\
\hline \multicolumn{4}{|l|}{ Number of children } \\
\hline One & 36.1 & 34.8 & \\
\hline Two & 37.7 & 40.7 & \\
\hline Three or more & 26.3 & 24.5 & .60 \\
\hline \multicolumn{4}{|l|}{$\begin{array}{c}\text { Child } \leq 5 \text { years of age living } \\
\text { in household? }\end{array}$} \\
\hline No & 48.4 & 43.0 & \\
\hline Yes & 51.6 & 57.0 & .07 \\
\hline \multicolumn{4}{|l|}{$\begin{array}{l}\text { Child with one or more } \\
\text { health/behavior problems }\end{array}$} \\
\hline No & 85.5 & 82.5 & \\
\hline Yes & 14.5 & 17.5 & .17 \\
\hline \multicolumn{4}{|l|}{$\begin{array}{c}\text { Parenting makes me tense and } \\
\text { anxious }\end{array}$} \\
\hline Disagree & 74.7 & 70.4 & \\
\hline Agree & 25.3 & 29.6 & .12 \\
\hline $\begin{array}{l}\text { Parenting is draining } \\
\text { (Mean \& SD) }\end{array}$ & $2.35(.90)$ & $2.25(.92)$ & .08 \\
\hline $\begin{array}{c}\text { Satisfaction with family-related } \\
\text { supports and services (Mean \& SD) }\end{array}$ & $3.13(1.18)$ & $3.25(1.20)$ & .09 \\
\hline $\begin{array}{l}\text { Help with daily chores } \\
\text { (Mean \& SD) }\end{array}$ & $3.15(1.30)$ & $3.31(1.30)$ & .04 \\
\hline Social support (Mean \& SD) & $19.43(4.16)$ & $18.41(4.12)$ & .00 \\
\hline \multicolumn{4}{|l|}{ Paid Work Characteristics } \\
\hline \multicolumn{4}{|l|}{ Long work hours $(50+$ hours/wk) } \\
\hline Yes & 13.65 & 25.93 & \\
\hline No & 86.35 & 74.07 & .00 \\
\hline \multicolumn{4}{|l|}{ Multiple job holder } \\
\hline Yes & 20.0 & 26.7 & \\
\hline No & 80.0 & 73.3 & .01 \\
\hline \multicolumn{4}{|l|}{ Work schedule } \\
\hline Regular daytime shift & 83.5 & 81.6 & \\
\hline Other & 16.5 & 18.4 & .40 \\
\hline Paid work demands (Mean \& SD) & $24.61(4.34)$ & $24.50(4.47)$ & .67 \\
\hline Decision latitude (Mean \& SD) & $26.59(4.83)$ & $25.49(5.81)$ & .01 \\
\hline \multicolumn{4}{|l|}{ Job Strain } \\
\hline High (high demands, low control) & 21.1 & 19.9 & \\
\hline Active (high demands, high control) & 31.9 & 30.3 & \\
\hline Passive (low demands, low control) & 23.7 & 27.7 & \\
\hline Low (low demands, high control) & 23.4 & 22.1 & .50 \\
\hline
\end{tabular}

Table 3.

Standardized (beta) coefficients for OLS regression of perceived time pressure on sociodemographic characteristics, role occupancy, family role characteristics and work role characteristics, women.

Step Variable $\quad$ Model 1 Model 2 Model 3 Model 4

1 Sociodemographic

Characteristics

\begin{tabular}{|c|c|c|c|c|}
\hline Age & -.02 & -.04 & -.03 & -.05 \\
\hline \multicolumn{5}{|l|}{$\begin{array}{l}\text { Educational } \\
\text { attainment }^{\mathrm{a}}\end{array}$} \\
\hline Some post-secondary & .04 & .05 & .04 & .04 \\
\hline $\begin{array}{l}\text { High school } \\
\text { or less }\end{array}$ & -.00 & .01 & -.01 & .00 \\
\hline Inadequate income $^{\mathrm{b}}$ & .08 & ${ }^{*} .09$ & .03 & .04 \\
\hline \multicolumn{5}{|l|}{$\begin{array}{l}\text { Role } \\
\text { Occupancy }\end{array}$} \\
\hline $\begin{array}{l}\text { Single } \\
\text { parent }^{\mathrm{c}}\end{array}$ & & -.03 & -.05 & -.07 \\
\hline Additional care giving & & ${ }^{* *} .13$ & ${ }^{* *} .15$ & ${ }^{* *} .16$ \\
\hline
\end{tabular}

3 Family Characteristics

Number

of children $^{\mathrm{d}}$

Two

$.06 \quad .05$

Three

$.02 \quad .04$

Child $<5$ years

of age living in $\quad .04 \quad .06$

household

Child has health

or behavioral problem

${ }^{* *} .11 \quad{ }^{* *} .11$

Parenting is

draining

${ }^{* *} .24 \quad{ }^{* *} .15$

Parenting is anxiety

provoking

Help with chores

${ }^{* *} .12 \quad * .22$

$-.03-.02$

Satisfaction with

amily-related

supports and services

$.00 \quad .01$

Social support

$-.08-.08$

4 Work

\section{Characteristics}

Long work hours

$-.04$

Non-regular

work schedule

Multiple job holder

.06

Job strain $^{\mathrm{e}}$

High

**. 19

Active

**. 15

Passive

\begin{tabular}{|c|c|c|c|}
\hline Adjusted $\mathrm{R}^{2}$ & .00 & .02 & .13 \\
\hline $\begin{array}{l}\text { (df) for Change } \\
\mathrm{R}^{2}\end{array}$ & $\begin{array}{c}1.22 \\
(4567)\end{array}$ & $\begin{array}{l}{ }^{* *} 5.16 \\
(2565)\end{array}$ & $\begin{array}{l}{ }^{* *} 8.94 \\
(9556)\end{array}$ \\
\hline
\end{tabular}

${ }^{a}$ Compared to university/college graduates; ${ }^{b}$ Compared to adequate income; ${ }^{\mathrm{C}} \mathrm{Compared}$ to partnered parent; ${ }^{\mathrm{d} C} \mathrm{Compared}$ to one child; ${ }^{\mathrm{e}} \mathrm{Compared}$ to low strain. ${ }^{*} \mathrm{p} \leq .05 ;{ }^{* *} \mathrm{p} \leq .01$. 
Table 4.

Standardized (beta) coefficients for OLS regression of perceived time pressure on sociodemographic characteristics, role occupancy, family role characteristics and work role characteristics, men.

\begin{tabular}{|c|c|c|c|c|c|}
\hline Step & Variable & Model 1 & Model 2 & Model 3 & Model 4 \\
\hline \multirow[t]{6}{*}{1} & $\begin{array}{l}\text { Sociodemographic } \\
\text { Characteristics }\end{array}$ & & & & \\
\hline & Age & .06 & .05 & .01 & -.04 \\
\hline & $\begin{array}{l}\text { Educational } \\
\text { attainment }^{\mathrm{a}}\end{array}$ & & & & \\
\hline & Some post-secondary & -.06 & -.05 & -.07 & -.09 \\
\hline & High school or less & -.02 & -.03 & -.02 & -.04 \\
\hline & Inadequate income ${ }^{\mathrm{b}}$ & -.04 & -.02 & -.03 & -.01 \\
\hline \multirow[t]{3}{*}{2} & Role Occupancy & & & & \\
\hline & Single parent ${ }^{\mathrm{c}}$ & & -.08 & ${ }^{*}-.13$ & ${ }^{*}-.13$ \\
\hline & $\begin{array}{l}\text { Additional care } \\
\text { giving }\end{array}$ & & -.04 & -.05 & -.06 \\
\hline \multirow[t]{11}{*}{3} & $\begin{array}{l}\text { Family } \\
\text { Characteristics }\end{array}$ & & & & \\
\hline & Number of children ${ }^{\mathrm{d}}$ & & & & \\
\hline & Two & & & .02 & .03 \\
\hline & Three & & & .10 & .11 \\
\hline & $\begin{array}{l}\text { Child } \leq 5 \text { years of } \\
\text { age living in } \\
\text { household }\end{array}$ & & & -.05 & -.08 \\
\hline & $\begin{array}{l}\text { Child has health or } \\
\text { behavioral problem }\end{array}$ & & & -.02 & -.01 \\
\hline & Parenting is draining & & & **.17 & $* .15$ \\
\hline & $\begin{array}{l}\text { Parenting is anxiety } \\
\text { provoking }\end{array}$ & & & .05 & .08 \\
\hline & Help with chores & & & .02 & .03 \\
\hline & $\begin{array}{l}\text { Satisfied with } \\
\text { family-related } \\
\text { supports and services }\end{array}$ & & & -.09 & -.08 \\
\hline & Social support & & & -.10 & -.09 \\
\hline \multirow[t]{10}{*}{4} & Work Characteristics & & & & \\
\hline & Long work hours & & & & .09 \\
\hline & $\begin{array}{l}\text { Non-regular work } \\
\text { schedule }\end{array}$ & & & & -.02 \\
\hline & Multiple job holder & & & & ${ }^{* *} .19$ \\
\hline & Job strain ${ }^{\mathrm{e}}$ & & & & \\
\hline & High & & & & ${ }^{* *} .23$ \\
\hline & Active & & & & ${ }^{* *} .21$ \\
\hline & Passive & & & & .05 \\
\hline & Adjusted $\mathbf{R}^{2}$ & -.00 & .00 & .06 & .14 \\
\hline & $\begin{array}{l}F(d f) \text { for } \\
\text { Change in } R^{2}\end{array}$ & $\begin{array}{c}.85 \\
(4385)\end{array}$ & $\begin{array}{c}1.60 \\
(2383)\end{array}$ & $\begin{array}{l}{ }^{* *} 3.75 \\
(9374)\end{array}$ & $\begin{array}{l}{ }^{* *} 6.27 \\
(6368)\end{array}$ \\
\hline
\end{tabular}

${ }^{\mathrm{a} C}$ Compared to university/college graduates; ${ }^{\mathrm{b}} \mathrm{Compared}$ to adequate income; ${ }^{\mathrm{C}} \mathrm{Compared}$ to partnered parent; ${ }^{\mathrm{d}} \mathrm{Compared}$ to one child; ${ }^{\mathrm{e}} \mathrm{Compared}$ to low strain. ${ }^{*} \mathrm{p} \leq .05 ;{ }^{* *} \mathrm{p} \leq .01$.

\section{Discussion}

The first aim of this study was to examine whether the addi- tional roles of caregiver and/or partner were associated with increased perceived time pressure among employed parents. Consistent with the results of previous, albeit limited, research (Beaujot \& Anderson, 2007; Hebert \& Grey, 2006), this study found the added responsibility of caregiver to be associated with higher levels of perceived time pressure among mothers. Interestingly, although similar proportions of mothers and fathers reported caregiving responsibilities in this study (about $6 \%$ ), the addition of the caregiving role was not associated with time pressure among fathers. Fast et al. (2002) reported a similar gender difference in their study of employed informal caregivers in Canada. These researchers found that a higher percentage of women $(65.4 \%)$ than men $(49.7 \%)$ reported difficulty balancing their multiple roles. In addition, almost one-half of the women in the study, compared to about one-third of the men, reported that their caregiving activities resulted in a lack of time for themselves.

What might account for this gender difference in the relationship between caregiving and perceived time pressure? The answer may lie in the gendered nature of unpaid caregiving work in Canada. In another Canadian study, Cranswick and Dosman (2008) reported that compared to male caregivers, female caregivers were more likely to perform: personal care activities (e.g. bathing, dressing), regularly scheduled housework tasks (e.g. meal preparation, laundry), tasks related to medical care, and overall coordination activities. Male caregivers were more likely than their female counterparts to perform tasks related to household maintenance and yard work. As Cranwick and Dosman (2008: p. 50) observe:

Not only are some of the tasks that women perform more personal, they also have to be performed according to a regular schedule, for example the administering of medicines and the preparation of meals. Other tasks such as care management must be done during the day when offices are open, competing with work time in the case of working caregivers. The timespecific nature of certain tasks is likely to add burden and stress to caregivers. In contrast, tasks outside the house such as house maintenance or outdoor work can usually wait until the care provider has the time to perform them.

As the North American population continues to age, informal caregiving demands will only increase, making the need for appropriate social and economic policies to assist informal caregivers with balancing their work and life responsibilities even more critical (Barrette, 2009; Cranwick \& Dosman, 2008; Duxbury et al., 2009).

In addition to the role of caregiver, this study also examined the relationship between perceived time pressure and occupancy of the marital/partner role among employed parents. Single-parent households, a growing family form in Canada, currently comprise about $17 \%$ of all families in Canada (Statistics Canada, 2008). Although most single parent households are led by women, the rate of single father headed households is growing in Canada more rapidly than single mother households. A prevalent assumption in the time pressure literature is that single mothers likely experience higher rates of time pressure than their partnered counterparts due to the absence of a live-in partner to share household and child rearing responsibilities (Barrette, 2009; Brooker \& Hyman, 2010). Single parents also have fewer financial resources than partnered parents (Williams, 2010), perhaps affording them less of an opportunity to "outsource" household work such as housework and yard work as a way of minimizing time pressure. In addition to financial con- 
straints, employed single parents are more likely than employed partnered parents to work in low-wage occupations which in turn are associated with more limited access to family-friendly policies which may facilitate balancing their work and family roles (Lambert, 1999; Mason, 2003). Surprisingly, however, the results of this study indicated no statistically significant association between perceived time pressure and lone motherhood; that is, employed single mothers reported a level of time pressure similar to that of partnered mothers. This finding is consistent with the results of some previous research (Baxter \& Alexander, 2008; Hebert \& Grey, 2006) but inconsistent with one other study that reported higher perceived time pressure among single compared to partnered mothers (Gunthorpe \& Lyons, 2004).

What might explain the lack of association between time pressure and single motherhood in this study? It is important to note that this study included only employed mothers and it is possible that single mothers who experience high levels of time pressure are unable to maintain employment and would therefore not have met the inclusion criteria for participation in this study. As concluded by Mason (2003: p. 49), in her qualitative study of 95 employed and non-employed lone mothers in several Canadian cities:

There were two major influences on a lone mother's ability to remain attached to the workforce: the presence of mothers, sisters or others able and willing to provide emergency childcare, and family-friendly work environments. Those without one or the other of these critical supports struggled and frequently withdrew from the paid labor force. Less critical, but still significant were factors associated with employment benefits, affordable housing, transportation, and recreation.

In other words, the sample in our study may be a very selective one whereby only those single mothers who have the necessary supports in place to be able to successfully balance the time demands of family and paid were likely included as study participants. Other research, though not specifically examining time pressure, provides an alternative view to understanding the lack of association between single motherhood and time pressure observed in this study. Some writers have been critical of what they consider a one-sided portrayal of single mothers in both the academic and popular press, that is, an "....almost exclusive focus on the dysfunctions and distress of single-parent families which does injustice to those solo parents who are relatively successful with regard to self-support and quality of life" (McManus, Korabik, Rosin, \& Kelloway, 2002: p. 1319). Indeed, some research does report that single mothers do not experience more difficulty than partnered mothers in balancing home and work life (McManus et al., 2002; Hertz \& Ferguson, 1998). The work, family, and community experiences of single mothers are likely diverse and unfortunately many studies, including this one, do not have detailed enough measures in place to reflect that diversity. The experience of time pressure is complex, and simply the occupancy or lack of occupancy of the partner role, fails to reflect that complexity. Unfortunately, with a few exceptions, quantitative research on time pressure has focused primarily on couple families (e.g. Deding \& Lausten, 2011; van der Lippe, 2007; Tezli \& Gauthier, 2009) and those that do consider marital status, often do not do so in combination with parent status (e.g. Roxburgh, 2002), or fail to distinguish between single mothers and single fathers (e.g. Gunthrope \& Lyons, 2004).

In contrast to mothers, partner status did make a difference for employed fathers, with single fathers in this study reporting significantly lower levels of perceived time pressure than partnered fathers. Similar to mothers is that this finding was somewhat unexpected. Although compared to single mothers, single fathers are more economically well-off (Williams, 2010), compared to partnered fathers, on the other hand, they are not (Galarneau, 2005). That is, Canadian data indicates that relative to couple fathers, single fathers have lower educational attainment, are less likely to be employed full-time, and are much more likely to be living in a low-income household (Williams, 2010; Galarneau, 2005). Thus, like single mothers, one might expect single fathers to be more pressed for time than fathers in couple households due in part to more limited access to the social and financial resources that could be used to minimize time pressures. However, the greater time pressure among partnered than single fathers in this study is consistent with the role scarcity perspective (Goode, 1960) which argues that occupying additional roles (in this case the partner role) should be associated with greater time pressure; that is, while a partner can be an important resource for balancing work and family obligations, fulfilling one's partner role responsibilities also requires time and effort. Single fathers' lower perceived time pressure may also be due to the fact that they are more likely than couple fathers to work part-time (Galarneau, 2005). Finally, some research suggests that single fathers may be less likely than other types of parents to spend time caring for their pre-school age children - a period in a child's life which typically requires daily, time-intensive parenting (Hook \& Chalasani, 2008). In addition, compared to partnered households, single fathers may spend more money on eating out rather than preparing food at home, perhaps resulting in less time pressure (Ziol-Guest, 2009).

Unfortunately, the measurement limitations in this study prevent a more in depth understanding of the reasons for the findings. Single parents in this study were those who indicated: being divorced/separated/widowed/never married, not living with a partner, and having a child living in their household at least "part of the time". Access to potentially important information, such as custody arrangements and the duration of single parenthood, were not available in the present study. Among single fathers there is obviously much variability in terms of their own and the other parent's level of involvement in their children's lives which would likely impact on fathers' experience of single parenting and the perception of being pressured for time. Also not addressed in the present study was the presence of other supportive people, such as grandparents, who may be available to assist employed single fathers in the daily demands of raising a family as a single parent.

The second aim of this study was to examine how family and work characteristics may be related to time pressure. Regarding family role characteristics, although neither the number of children nor the presence of a young child were associated with time pressure for parents in this study, perceptions of time pressure did increase for mothers who were the parent of a child with a health and/or behavioral problem. Parenting a child with health or behavioural issues was not associated with time pressure for fathers. Although similar proportions of mothers and fathers in this study reported this family circumstance (see Table 2), no information was collected regarding the amount of time actually spent on parenting a child with such challenges. Given that gender influences both the amount and type of care giving provided in families (Dufur, 2009), it is possible that 
mothers in this study may take on a larger share of the responsibilities or "case management" for these children than fathers. Mothers may report feeling time pressured because of the additional cognitive planning that would be needed to deal with illness or behavioural issues, not to mention perhaps time spent communicating with schools and/or the health care sector. Gender differences also emerged in regard to subjective family characteristics. Again, although similar proportions of mothers and fathers agreed with various statements that parenting was emotionally draining or anxiety-provoking (Table 2), such perceptions were related to mothers' but not fathers' experience of time pressure.

Why might the perception of parenting as anxiety provoking be associated with greater perceived time pressure among employed mothers than fathers? This question is difficult to answer. The single item measures of parental role quality used in this study pose challenges to their meaningful interpretation. The cross-sectional nature of the study also adds to the challenge: does feeling time pressured lead to the perception of parenting as exhausting or visa versa? Compared to mothers who disagree with such statements, it is plausible that mothers' who agree, for a variety of reasons, spend more of their time in parenting-related activities, leading to perceptions of time pressure. Perhaps mothers who perceive parenting as exhausting and/or anxiety provoking have fewer economic and social resources at their disposal, making it more difficult to fulfill their parenting responsibilities in a time-efficient manner. It is important to note, however, that mothers' perceptions of parenting quality in this study remained statistically significantly associated with time pressure, even after adjusting for other characteristics which may differ between women in this study and be related to time pressure, such as the availability of social support and various employment characteristics. Additional research is needed to understand this finding.

Interestingly, more tangible types of support, such as satisfaction with family-related supports and services in the community and help with household chores, were not associated with mothers' or fathers' experience of time pressure. Regarding the latter finding, although previous research has reported actual time in unpaid family work as quite consistently associated with perceived time pressure among women (Deding \& Lauston, 2011; Hebert \& Grey, 2006), research using measures assessing relative contribution to paid and domestic work (i.e., the division of labour) have produced more ambiguous results (Beujot \& Anderson, 2006; Tezli \& Gauthier, 2009). The lack of association in our study between tangible social supports and time pressure may be due, in part, to our use of relatively crude, single item measures of both unpaid family work demands and availability of family services.

In contrast to family characteristics, fewer gender differences emerged in the relationship between paid work characteristics and mothers' and fathers' perceptions of time pressure. Objective job characteristics in this study, with the exception of holding down multiple jobs among men, were unrelated to perceptions of time pressure. The relationship observed in this study between multiple job occupancy and time pressure seems a reasonable one, due to the time splitting required between being at two (or more) places of employment, along with the additional role of being a parent. For both mothers and fathers in this study, high strain jobs (i.e., high demands, low control) were associated with greater time pressure. Workers in high strain jobs would have greater perceptions of things being hec- tic, having to work fast, and being frequently interrupted when trying to complete their work tasks (Karasek et al., 1998). Such workers would also have less access to resources that might assist them in coping with a psychologically demanding job, such as the freedom to make work-related decisions on their own and a say about what happens on their job. Thus, the statistically significant association observed both in this study and in Roxburgh's (2002) between high demands/low control and increased perceptions of time pressure, seems quite logical. Some research suggests that a highly strained paid work environment increases workers' perceptions of work-family conflict (Neil \& Hammer, 2007), which in turn, may increase perceptions of time pressure.

\section{Study Limitations}

There are a number of limitations to this study both in design and measurement. This study is cross-sectional, and therefore, there was not enough evidence to establish the temporal relationship between perceptions of time pressure on the one hand and work and family role occupancies/characteristics on the other. Although the perception of time pressure was positioned as the dependent variable in this study, based on previous published literature in the area, time pressure could plausibly act as in independent variable in some of the relationships examined here (e.g. perceptions of parenting quality). In addition, individuals' work and family role occupancies and their associated characteristics are not static, but rather, change over time; the inability of this study to capture the dynamic nature of work and family roles in relation to perceptions of time pressure also limit the ability to draw any causal conclusions. More research with diverse samples of participants, in terms of life stage, family composition, sexual orientation, ethnicity, and socioeconomic position, is required to advance the field.

The quality of family and paid work roles in the study were considered to be a function of a combination of subjective and objective role characteristics (Neal \& Hammer, 2007). Although the measurement of several of the objective paid work characteristics was relatively crude (e.g. work hours, nonstandard work), the use of Karasek's job strain measure in this study, given its strong theoretical and research base, was a strength. On the other hand, the quality of measures of family characteristics was weaker. Several single item measures were used in this study as indicators of family role quality, such as the extent to which participants endorsed several statements regarding their parenting role. The interpretation of the results of this study could have definitely been strengthened with the use of a theoretically-based, psychometrically sounder measure of family role quality.

Finally, it is important to note that although statistically significant associations were reported in the study between work and family role occupancies/characteristics and perceived time pressure, the predictor variables only explained a modest amount (about 15\%) of the total variability in the dependent variable. Obviously, there are other factors associated with perceived time pressure that were not included in this study and need to be addressed in future research, such as the number of daily activities, general health, and the occupancy of other roles such as volunteer. The inclusion of more valid and reliable measures of the family and paid work role characteristics would also enhance the explanatory power of our multivariable models of time pressure. 


\section{Conclusion}

The overall aim of this study was to better understand the patterning of perceived time pressure among working mothers and fathers in Canada according to whether they occupied the additional role of partner and/or caregiver, as well as according to characteristics associated with their paid work and family roles. The main finding of this study is that both role occupancy and role quality is related to perceived time pressure among employed parents and that the precise nature of these relationships depends on gender. However, more longitudinal research, combined with the greater use of psychometrically sound and theoretically-informed measures of time pressure and family work, is required to advance the field.

Although study limitations temper firm conclusions, the results do have implications for the development of work and family policy. To enhance the psychosocial paid work environment of parents, job redesign practices that could reduce workplace stress may include increasing the employees' overall job control, skill use, and reducing work-role conflict, by encouraging employees to be more active in decision making processes (Lowe, 2007). Additional support by governments could reduce caregiver burden by programs that provide respite and assistance in arranging seniors move into care facilities. To assist mothers in the early years of raising children, adequate access to affordable child-care is critical (Brooker \& Hyman, 2010). The availability of high quality and affordable early childhood education and care can have a major impact on parents (and children's) quality of life, by reducing family caregiving demands and altering how young children spend their time.

\section{REFERENCES}

Barrette, J. (2009). Work/family balance: What do we really know? Contemporary family trends. The Vanier Institute of the Family. URL (last checked 17 December 2011).

http://www.vifamily.ca/sites/default/files/work_family_balance_1.pd $\mathrm{f}$

Baxter, J., \& Alexander, M. (2008). Mothers' work-to-family strain in single and couple parent families: The role of job characteristics and supports. Australian Journal of Social Issues, 43, 195-214.

Beaujot, R., \& Andersen, R. (2007). Time-crunch: Impact of time spent in paid and unpaid work, and its division in families. Canadian Journal of Sociology, 32, 295-315. doi:10.2307/20460645

Bellavia, G., \& Frone, M. (2005). Work-family conflict. In J. Barling, E. K. Kelloway, \& M. Frone (Eds.), Handbook of work stress (pp. 185-221). Thousand Oaks, California: Sage Publications.

Berkman, S., \& The ENRICHD Investigators (2001). Enhancing recovery in coronary heart disease (ENRICHD): Baseline characteristics. The American Journal of Cardiology, 88, 316-322. doi:10.1016/S0002-9149(01)01652-6

Brooker, A., \& Hyman, I. (2010). Time use: A report of the Canadian index of wellbeing (CIW). URL (last checked 17 December 2011). http://ciw.ca/reports/en/Domains\%20of\%20Wellbeing/TimeUse/Tim e_Use-Full_Report.sflb.pdf

Cranswick, K., \& Dosman, D. (2008). Eldercare: What we know today. Canadian social trends, statistics Canada catalogue number 11-008-X. Ottawa. URL (last checked 17 December 2011).

http://www.statcan.gc.ca/pub/11-008-x/2008002/article/10689 -eng.pdf

Deding, M., \& Lausten, M. (2011). Gender time-crunch and work factors in Denmark. Social Indicators Research, 101, 249-253. doi:10.1007/s11205-010-9643-2

Dufur, J., Howell, C., Downey, B., Ainsworth, W., \& Lapray, A. (2010). Sex difference in parenting behaviours in single-mother and sin- gle-father households. Journal of Marriage and Family, 72, 10921106. doi:10.1111/j.1741-3737.2010.00752.x

Duxbury, L., \& Higgins, C. (2009). Work-life conflict in Canada in the new millennium. Key findings and conclusions from the $2001 \mathrm{Na}-$ tional Work-Life Conflict Study. Ottawa. URL (last checked 17 December 2011)

http://www.hc-sc.gc.ca/ewh-semt/pubs/occup-travail/balancing_six-e quilibre_six/index-eng.php

Dziak, E., Janzen, B., \& Muhajarine, N. (2010). Inequalities in the psychological well-being of employed, single and partnered mothers: The role of psychosocial work quality and work-family conflict. International Journal for Equity in Health, 9, 1-8.

Fast, J., \& Frederick, J. (1998). The time of our lives: Juggling work and leisure over the life cycle. Statistics Canada Catalogue Number 89-584-MI.E. Ottawa. URL (last checked 17 December 2011). http://dsp-psd.pwgsc.gc.ca/Collection/Statcan/89-584-M/89-584-MI E2003004.pdf

Galarneu, D. (2005). Education and income of lone parents. Perspectives in Labour and Income, 6, 5-1.

Goode, W. (1960). A theory of role strain. American Sociological Review, 25, 483-496. doi:10.2307/2092933

Griffin, J., Fuhrer, R., Stansfeld, S., \& Marmot, M. (2002). The importance of low control at work and home on depression and anxiety: Do these effects vary by gender and social class? Social Science \& Medicine, 54, 783-798. doi:10.1016/S0277-9536(01)00109-5

Gunthorpe, W., \& Lyons, K. (2004). A predictive model of chronic time pressure in the Australian population: Implications for leisure research. Leisure Sciences, 26, 201-213. doi:10.1080/01490400490432127

Hébert, B. P, \& Grey, A. (2006). Time-related stress: Incidence and risk factors. Horizons, 8, 14-23.

Hertz, R., \& Ferguson, F. (1998). Only one pair of hands: Ways that single mothers stretch work and family resources. Community, Work \& Family, 1, 13-37. doi:10.1080/13668809808414695

Neal, M., \& Hammer, L. (2007). Working couples caring for children and aging parents. New Jersey: Lawrence Erlbaum Associates.

Hilbrecht, M. (2009). Parents, employment, gender and well-being: A time use study. Ph.D. Thesis, Waterloo: University of Waterloo.

Hook, J., \& Chalassani, S. (2008). Gender expectations? Reconsidering fathers' child-care time. Journal of Marriage and Family, 70, 978990. doi:10.1111/j.1741-3737.2008.00540.x

Jacobs, J. A., \& Gerson, K. (2005). The time divide: Work, family and gender inequality. Cambridge: Harvard University Press.

Karasek, R., Brisson, C., Kawakami, N., Houtman, I., Bongers, P., \& Amick, B. (1998). The job content questionnaire: An instrument for internationally comparative assessments of psychosocial job characteristics. Journal of Occupational Health Psychology, 3, 322-355. doi:10.1037/1076-8998.3.4.322

Lambert, S. (1999). Lower-wage workers and the new realities of work and family. Annals of the American Academy of Political and Social Science, 562, 174-190. doi:10.1177/0002716299562001012

Lowe, G. (2007). 21st century job quality: Achieving what Canadians want. Canadian Research Policy Networks. URL (last checked 17 December 2011).

http://www.cprn.org/documents/48485_EN.pdf

MacDonald, M., Phipps, S., \& Lethbridge, L. (2005). Taking its toll: The influence of paid and unpaid work on women's well-being. Feminist Economics, 11, 63-95. doi:10.1080/1354570042000332597

Mason, R. (2003). Listening to lone mothers: Paid work, family life and childcare in Canada. Journal of Children and Poverty, 9, 41-54. doi:10.1080/1079612022000052715

Marshall, K. (2006). Converging gender roles. Statistics Canada Catalogue Number 75-001-XI.E. Ottawa. URL (last checked 17 December 2011). http://statcan.gc.ca/pub/75-001-x/10706/9268-eng.pdf

Mattingly, M. J., \& Sayer, L. C. (2006). Under pressure: Gender differences in the relationship between free time and feeling rushed. Journal of Marriage and Family, 68, 205-221. doi:10.1111/j.1741-3737.2006.00242.x

McManus, K., Korabik, K., Rosin, H., \& Kelloway, E. (2002). Employed mothers and the work-family interface: Does family structure matter? Human Relations, 55, 1295-1324. 
doi: $10.1177 / 0018726702055011919$

Milkie, M., Mattingly, M., Nomaguchi, K., Bianchi, S., \& Robinson, J. (2004). The time squeeze: Parental statuses and feelings about time with children. Journal of Marriage and Family, 66, 739-761. doi:10.1111/j.0022-2445.2004.00050.x

Nomaguchi, K. M., Milkie, M. A., \& Bianchi, S. M. (2005). Time strains and psychological well-being: Do dual-earner mothers and fathers differ? Journal of Family Issues, 26, 756-792. doi: $10.1177 / 0192513 \times 05277524$

Roxburgh, S. (2002). Racing through life: The distribution of time pressures by roles and role resources among full-time workers. Journal of Family and Economic Issues, 23, 121-145. doi:10.1023/A:1015734516575

Roxburgh, S. (2004). 'There just aren't enough hours in the day: The mental health consequences of time pressure. Journal of Health and Social Behavior, 45, 115-131. doi:10.1177/002214650404500201

Stansfeld, S., \& Candy, B. (2006). Psychosocial work environment and mental health-A meta-analytic review. Scandinavian Journal of Work, Environment \& Health, 32, 443-462.

doi:10.5271/sjweh.1050

Statistics Canada (2005). Canadian Community Health Survey, Cycle 3.1 (2005). Public use microdata file documentation. Ottawa, ON: Author.

Statistics Canada (2008). Families, households, and housing: Overview. Canada Yearbook. Statistics Canada Catalogue Number 97-553XI.E. Ottawa, ON. URL (last checked 17 December 2011). http://www.statcan.gc.ca/pub/11-402-x/2011000/pdf/families-famille s-eng.pdf

Tezli, A., \& Gauthier, A. (2009). Balancing work and family in Canada. An empirical examination of conceptualizations and measurements. Canadian Journal of Sociology, 34, 433-461. van der Lippe, T. (2007). Dutch workers and time pressure: Household and workplace characteristics. Work, Employment \& Society, 21, 693-711. doi:10.1177/0950017007082877

Vermeulen, M., \& Mustard, C. (2000). Gender differences in job strain, social support at work, and psychological distress. Journal of Occupational Health Psychology, 5, 428-440. doi:10.1037/1076-8998.5.4.428

Voydanoff, P. (2005). The differential salience of family and community demands and resources for family to work conflict and facilitation. Journal of Family and Economic Issues, 26, 395-417. doi:10.1007/s10834-005-5904-7

Tao, W., Janzen, B., \& Abonyi, S. (2010). Gender, division of unpaid family work and psychological distress in dual-earner families. Clinical Practice \& Epidemiology in Mental Health, 6, 36-46. doi:10.2174/1745017901006010036

Williams, C. (2010). Women in Canada: A gender-based statistical report. Economic well-being. Statistics Canada Catalogue Number 89-503-X. Ottawa, ON. URL (last checked 17 December 2011). http://www.statcan.gc.ca/pub/89-503-x/2010001/article/11388-eng.ht $\mathrm{m}$

Ziol-Guest, K. (2009). A single father's shopping bag: Purchasing decisions in single-father families. Journal of Family Issues, 30, 605-622. doi:10.1177/0192513X08331022

Zukewich, N. (2003). Unpaid informal caregiving. Statistics Canada Catalogue Number 11-008. Ottawa. URL (last checked 17 December 2011).

http://www.statcan.gc.ca/pub/11-008-x/2003002/article/6622-eng.pdf

Zuzanek, J. (2004). Work, leisure, time pressure and stress. In J. T. Haworth, \& A. J. Veal (Eds.), Work and leisure (pp. 123-144). London: Routledge. 